\title{
Structural characteristics and antiviral activity of multiple peptides derived from MDV glycoproteins $\mathrm{B}$ and $\mathrm{H}$
}

\author{
Xiaojia Wang ${ }^{*}$, Xiaojing $\mathrm{Chi}^{\dagger}$ and Ming Wang ${ }^{*}$
}

\begin{abstract}
Background: Marek's disease virus (MDV), which is widely considered to be a natural model of virus-induced lymphoma, has the potential to cause tremendous losses in the poultry industry. To investigate the structural basis of MDV membrane fusion and to identify new viral targets for inhibition, we examined the domains of the MDV glycoproteins $\mathrm{gH}$ and $\mathrm{gB}$.

Results: Four peptides derived from the MDV glycoprotein $\mathrm{gH}(\mathrm{gHH} 1, \mathrm{gHH} 2, \mathrm{gHH}$, and $\mathrm{gHH} 5)$ and one peptide derived from $\mathrm{gB}(\mathrm{gBH} 1)$ could efficiently inhibit plaque formation in primary chicken embryo fibroblast cells (CEFs) with $50 \%$ inhibitory concentrations $\left(I_{50}\right)$ of below $12 \mu \mathrm{M}$. These peptides were also significantly able to reduce lesion formation on chorioallantoic membranes (CAMs) of infected chicken embryos at a concentration of $0.5 \mathrm{mM}$ in $60 \mu \mathrm{l}$ of solution. The HR2 peptide from Newcastle disease virus (NDVHR2) exerted effects on MDV specifically at the stage of virus entry (i.e., in a cell pre-treatment assay and an embryo co-treatment assay), suggesting crossinhibitory effects of NDV HR2 on MDV infection. None of the peptides exhibited cytotoxic effects at the concentrations tested. Structural characteristics of the five peptides were examined further.

Conclusions: The five MDV-derived peptides demonstrated potent antiviral activity, not only in plaque formation assays in vitro, but also in lesion formation assays in vivo. The present study examining the antiviral activity of these MDV peptides, which are useful as small-molecule antiviral inhibitors, provides information about the MDV entry mechanism.
\end{abstract}

Keywords: Marek?'?s disease virus glycoprotein, plaque formation, chorioallantoic membrane, structural characteristics, antiviral inhibitor, viral entry mechanism

\section{Background}

The entry of enveloped viruses into host cells occurs via fusion of the viral envelope with the cellular membrane. This membrane fusion is mediated by several glycoproteins in the viral envelope that overcome strong repulsive hydration forces as well as steric and electrostatic barriers. Several of the functional motifs present in different viral fusion glycoproteins are drug development targets [1].

Herpesviruses are structurally complex enveloped viruses that have at least twelve glycoproteins on their

\footnotetext{
*Correspondence: wangxj@cau.edu.cn; vetdean@cau.edu.cn

† Contributed equally

Key Laboratory of Zoonosis of Ministry of Agriculture, College of Veterinary Medicine, China Agricultural University, No. 2, Yuan Ming Yuan West Road, Haidian District, Beijing 100193, PR China
}

surfaces. Unlike orthomyxoviruses, paramyxoviruses, filoviruses, and retroviruses, which all use a single fusion glycoprotein for membrane fusion, herpesviruses use a conserved core fusion machinery consisting of the glycoprotein $\mathrm{gB}$ and a $\mathrm{gH}$-gL heterodimer [2]. $\mathrm{gB}$ is a class III viral fusion protein, also called a fusogen, that is presumably directly involved in bringing the viral and cellular membranes together but cannot function on its own $[3,4]$. The crystal structure of the gH ectodomain bound to gL shows an unusually tight complex with a unique architecture; and the formation of a gB-gH-gL complex is critical for membrane fusion [5]. The fusion machinery of herpesviruses is more complex than that of most enveloped viruses and is somewhat reminiscent of the fusion machinery involved in cellular fusion processes 
[6-9]. In some herpesviruses, both $\mathrm{gH}$ and $\mathrm{gB}$ possess heptad repeat $(\mathrm{HR})$ regions, and the peptides from HR regions have been shown to inhibit fusion [10-12]. Furthermore, it has been shown that the $\alpha$-helix rich and hydrophobic regions of viral fusion proteins may be required for efficient induction of fusion [13-16].

Marek's disease virus (MDV) has long been of interest as a model organism, particularly with respect to the pathogenesis and immune control of virus-induced lymphoma in an easily accessible small animal system. MDV was long thought to be related to Epstein-Barr virus (EBV), a member of the Gammaherpesvirinae family, owing to its biological properties, particularly its slow growth in culture and its ability to induce T-cell lymphoma. Electron microscopy studies of the MDV genome provided the first evidence that this doublestranded DNA virus possesses repeat structures that are characteristic of the Alphaherpesvirinae, which was later confirmed by detailed restriction mapping and sequencing of individual genes and then entire genomes. It is now known that MDV is genetically closely related to human herpesvirus 1 (herpes simplex virus type 1, HSV1 ) and human herpesvirus 3 (varicella-zoster virus, VZV) [17]. Recent advances in MDV genetics and the sequencing of the chicken genome, aided by functional genomics have increased our understanding of lytic MDV replication and the factors and mechanisms leading to latency and tumour formation $[17,18]$. MDV is found in all areas of the world and particularly virulent forms of this virus frequently cause acute explosive outbreaks, despite the availability of vaccines. The nononcogenic MDV strains used as a vaccine prevent tumour growth but do not prevent the replication of either vaccine or virulent strains, and infectious virus particles survive at room temperature for several months [19]. To understand the molecular mechanisms of MDV entry into host cells and to potentially identify inhibitory agents, we sought to determine the functional roles of specific regions of $\mathrm{gH}$ and $\mathrm{gB}$ proteins involved in the membrane fusion process [20,21].

\section{Results}

MDV $\mathrm{gH}$ and $\mathrm{gB}$ have serial HR regions showing potential antiviral activity

In this study, we searched for HR regions in MDV gH and $\mathrm{gB}$ proteins using a series of biological software packages. Six potential HR regions in $\mathrm{gH}$ and five potential HR regions in $\mathrm{gB}$ were identified (see Figure 1). To determine whether these peptides could affect virus infectivity, primary CEFs were incubated with peptides at increasing concentrations in the presence of $100 \mathrm{pfu}$ MDV (i.e., the co-treatment assay). The cells were then incubated for 5 days at $37^{\circ} \mathrm{C}$ in DMEM supplemented with $2 \%$ FCS, and plaques were counted. Plaque formation is shown in Figure 2a. We also used an immunofluorescence (IFA) assay with anti-pp24 antibody to verify plaque formation [22] (see Figure 2b). Uninfected cells resembled cells in which plaque formation was inhibited, and they are not shown here. These experiments demonstrate that peptides gHH4, gHH6, and $\mathrm{gBH} 2-5$ could inhibit plaque formation at an $\mathrm{IC}_{50}$ of more than $25 \mu \mathrm{M}$. Five peptides (gHH1, gHH2, gHH3, gHH5, and gBH1) with $\mathrm{IC}_{50}$ values below $12 \mu \mathrm{M}$ were selected for further studies. The $\mathrm{IC}_{50}$ values of gHH1, gHH2, gHH3, gHH5, and gBH1 were approximately $4,8,12,8$ and $9 \mu \mathrm{M}$, respectively. These results are shown in Figure 2c. In addition, gHH6 was considered for further analysis in current study because its hydrophilic character is similar to the most potent inhibitor gHH1, and they were two HR domains with the highest predicted tendency to form coiled-coil structures (see Figure 1c).

All of the GST fusion proteins used in this study were expressed as soluble proteins. The cleaved proteins were highly soluble in PBS at concentrations of about $1 \mathrm{mg} /$ $\mathrm{ml}$. SDS-PAGE gels of the five GST fusion proteins and corresponding cleaved proteins are shown in Figure 3.

\section{gHH1, gHH2, gHH3, gHH5, and gBH1 have potent antiviral activities at different steps of the viral entry process}

A plaque formation experiment was conducted to identify which steps in the entry process were inhibited by gB- and gH-derived peptides at a concentration of 25 $\mu \mathrm{M}$, the concentration which induced significant inhibition, and to compare the effect of different four methods without a strong bias. Four different assays were conducted: cells were exposed to peptides at different concentrations prior to infection (cell pre-treatment), during entry (co-treatment), after viral entry (post-treatment), or when the virus was pre-incubated with the peptide for 1 hour at $37^{\circ} \mathrm{C}$ before attaching to the cells (virus pre-treatment). After all treatments, the cells were incubated for 5 days at $37^{\circ} \mathrm{C}$ in DMEM supplemented with FCS and plaque numbers were then determined. All five peptides showed potent antiviral activity in the co-treatment experiment and inhibited infection to a minor extent in other assays. These results demonstrate that at $25 \mu \mathrm{M}, \mathrm{gHH} 1$ was the most effective peptide in the post-treatment assay with $100 \%$ inhibition of plaque formation. Plaque formation was completely inhibited by the gHH2 peptide at $25 \mu \mathrm{M}$ in a virus pre-treatment assay. In addition, all five peptides tested inhibited plaque formation $60-80 \%$ in the co-treatment assay at a concentration of $25 \mu \mathrm{M}$. Furthermore, plaque formation was completely inhibited by gHH1 at $50 \mu \mathrm{M}$ in the cotreatment assay and plaque formations of $\mathrm{gHH} 2, \mathrm{gHH} 3$, gHH5, and gBH1 were nearly $20 \%, 20 \%, 13 \%$, and $12 \%$ 

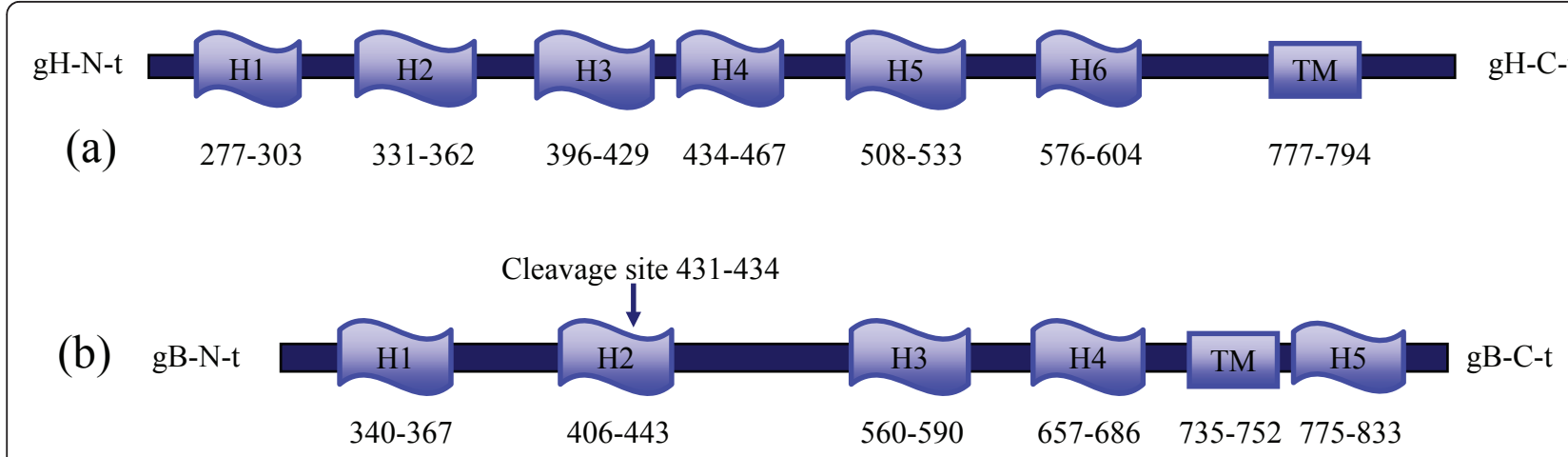

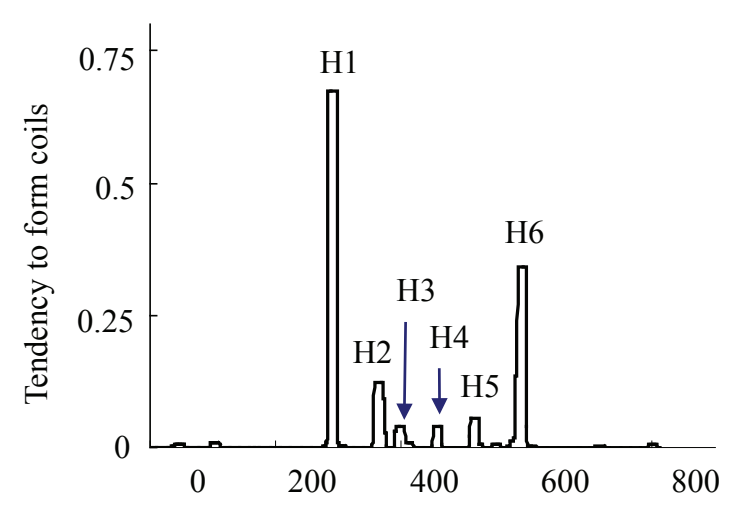

(c)

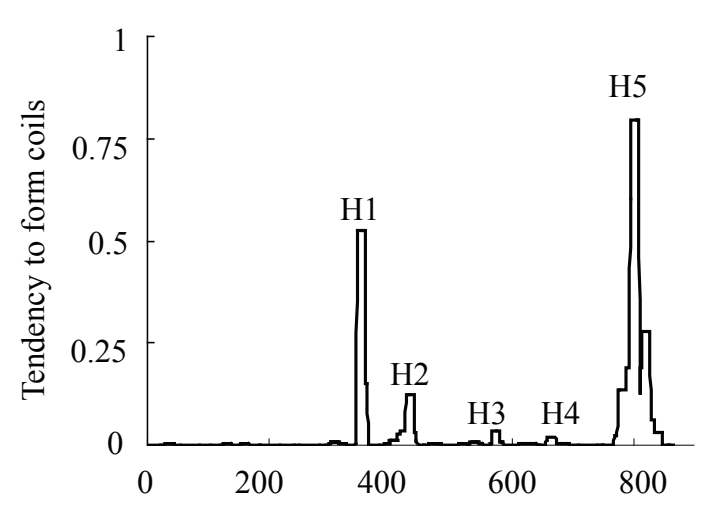

(d)

Amino acid residue of MDV gB

Figure 1 Prediction of functional domains of MDV $\mathbf{g H}$ and $\mathbf{g B}$. (a) Linear representation of the MDV gH glycoprotein including potential HR regions and transmembrane region (TM). (b) Linear representation of the MDV gB glycoprotein including potential HR regions and TM region. gBH2 domain contains cleavage site located at aa residues 431 to 434. (c) Six HR domains of MDV gH as predicted by the ExPASy-Coils program. (d) Five HR domains of MDV gB as predicted by the ExPASy-Coils program.

at $50 \mu \mathrm{M}$. These results indicate that gHH1 and gHH2 should be the most effective peptides from this study for small-molecule antiviral drug design to inhibit MDV entry. Finally, the HR2 region from the fusion glycoprotein (gF) of Newcastle disease virus (NDV) (NDVHR2) at $25 \mu \mathrm{M}$ demonstrated antiviral activity with $20 \%$ plaque formation, more effective than MDV-derived peptides, when used prior to MDV entry into cells (i.e., in the cell pre-treatment assay)." NDVHR1 and gHH6 (the negative controls) did not show significant antiviral activity, demonstrating the specificity of the antiviral effect of the MDV-derived peptides used in this study. These results are shown in Figure 2d.

\section{None of the peptides exhibit cytotoxic effects}

To confirm that these peptides did not exert toxic effects on CEF cells, cell monolayers were exposed to a range of concentrations $(5,25,50,100,250,500 \mu \mathrm{M}$, and $1.0 \mathrm{mM}$ ) of each peptide for 24 hours, and the cell viability was analysed using the lactate dehydrogenase (LDH) assay. There was no statistically significant difference between the viability of the control (untreated) cells and the cells exposed to the peptides. None of the peptides exhibited cytotoxic effects at the concentrations tested (data not shown). In addition, peptides at a $1.0 \mathrm{mM}$ dosage did not exhibit any side effects on MDV-uninfected or infected embryos, including no effect on embryo activity and no apparent pathological changes.

$\mathrm{gHH} 1, \mathrm{gHH} 2, \mathrm{gHH} 3, \mathrm{gHH} 5$, and $\mathrm{gBH} 1$ have potent antiviral effects on lesion formation

We next examined the antiviral effects of these peptides on chorioallantoic membrane (CAM) lesion formation. Briefly, various concentrations of peptides $(0.1,0.5$, or $1.0 \mathrm{mM}$ ) in $60 \mu \mathrm{l}$ of solution were mixed with $10^{3} \mathrm{pfu}$ of virus and injected into the yolk sacs of 6-7-day-old embryonated chicken eggs (for the co-treatment assay), or yolk sacs were infected with virus for 1.5 hours at $37^{\circ}$ $\mathrm{C}$ before peptides were administered (for the post-treatment assay). After 9 days, the CAMs were harvested and lesion formation was measured. The mean of 63 


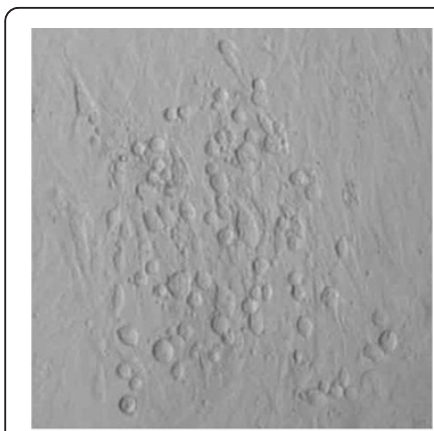

(a) plaque formation

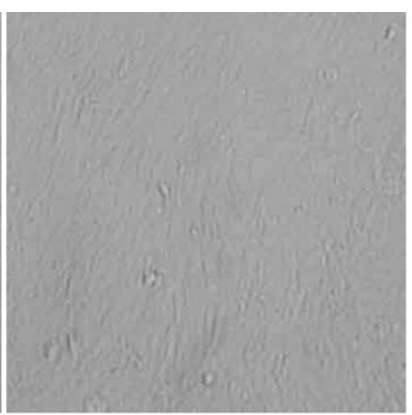

plaque formation inhibition
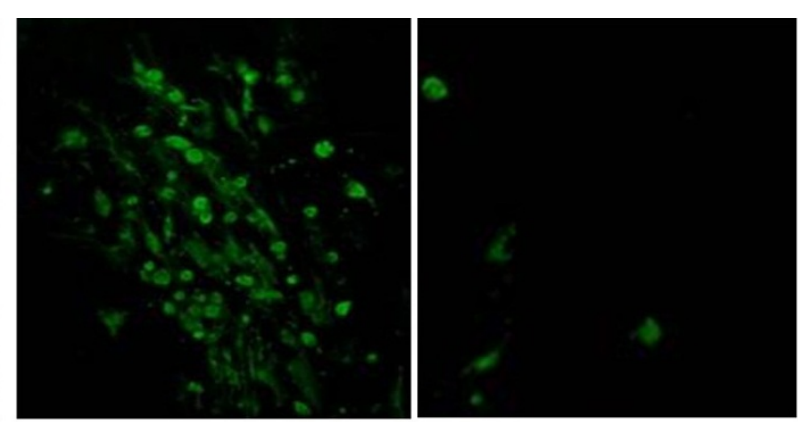

(b) plaque formation by IFA plaque inhibition by IFA
Virus pre - $\square$ Cell pre- $\square$ Co- $\square$ Post-

\begin{tabular}{|c|c|c|c|}
\hline peptides & $\mathrm{IC}_{50}$ & peptides & $\mathrm{IC}_{50}$ \\
\hline gHH1 & $4 \pm 0.26 \mu \mathrm{M}$ & gBH1 & $9 \pm 0.27 \mu \mathrm{M}$ \\
\hline gHH2 & $8 \pm 0.24 \mu \mathrm{M}$ & $\mathrm{gBH} 2$ & $>25 \mu \mathrm{M}$ \\
\hline gHH3 & $12 \pm 0.8 \mu \mathrm{M}$ & $\mathrm{gBH} 3$ & $>25 \mu \mathrm{M}$ \\
\hline gHH4 & $>25 \mu \mathrm{M}$ & $\mathrm{gBH} 4$ & $>25 \mu \mathrm{M}$ \\
\hline gHH5 & $8 \pm 0.48 \mu \mathrm{M}$ & gBH5 & $>25 \mu \mathrm{M}$ \\
\hline gHH6 & $>25 \mu \mathrm{M}$ & NHR2 & $>25 \mu \mathrm{M}$ \\
\hline
\end{tabular}

(c)

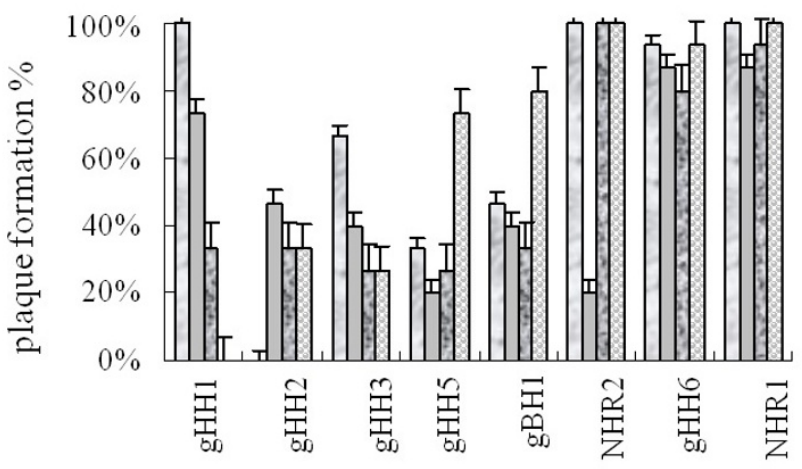

(d) peptide concentration $(25 \mu \mathrm{M})$

Figure 2 Effect of peptides on plaque formation. (a) Photos show plaque formation at $10 \times 10$ magnification (infected by 100 pfu of MDV without peptides, i.e., 100\% plaque formation) and 0\% plaque formation (infected by 100 pfu MDV with $50 \mu \mathrm{M}$ gHH2 in cell-pre treatment assay, i.e., 100\% plaque formation inhibition). (b) The plaque formation using immunofluorescent (IFA) staining with 1:100 diluted antibody anti-pp24, and plaque formation inhibition are shown from left to right, respectively. (c) Five peptides $(\mathrm{gHH} 1, \mathrm{gHH} 2, \mathrm{gHH} 3, \mathrm{gHH}$, and $\mathrm{gBH} 1)$ with $\mathrm{IC}_{50}$ values below $12 \mu \mathrm{M}$ were selected for further study. In addition, NHR2 (i.e. NDV HR2) and gHH6 were selected as control proteins in the paper. Note: The $I C_{50}$ are the means \pm standard deviations determined from three independent experiments. (d) CEF cells were exposed to peptides at concentration of $25 \mu \mathrm{M}$ either prior to infection (cell pre-treatment, cell pre-), during entry (co-treatment, co-) or after virus penetration (posttreatment, post-), or alternatively, the virus was pre-incubated with peptides for $1 \mathrm{~h}$ at $37^{\circ} \mathrm{C}$ before addition to the cells (virus pre-treatment, virus pre-). Experiments were performed in triplicate, and the plaque formation percentages were calculated. Peptides $\mathrm{gHH} 1, \mathrm{gHH} 2, \mathrm{gHH} 3, \mathrm{gHH}$, $\mathrm{gBH1}$, NHR2, gHH6, and NHR1 (i.e. NDV HR1) are shown from left to right, respectively.

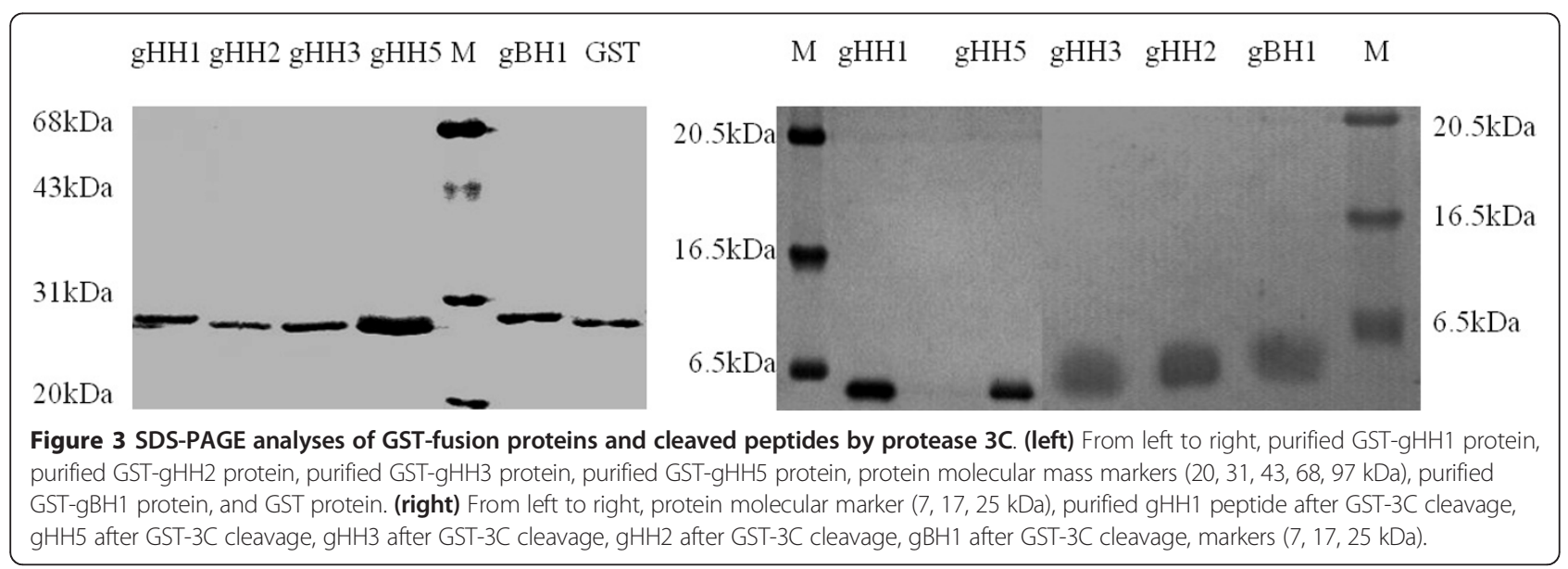


no-peptide control lesions per membrane was determined to be very reproducible. All peptides showed dose-dependent activity against lesion formation, and gHH1 and gHH2 were particularly effective at inhibiting infection in both virus co-treatment and post-treatment assays. Lesion formation was completely inhibited by the gHH1 peptide in the post-treatment assay and by gHH2 in the co-treatment assay at a concentration of $1.0 \mathrm{mM}$. Interestingly, NDVHR2 at $1.0 \mathrm{mM}$ showed effective antiviral activity against MDV only in the co-treatment assay with reduction of lesion formation to $15 \%$. In addition, the non-specific protein NDVHR1 and gHH6 did not show significant antiviral activity in either assay. These results are presented in Figure 4.

\section{Structural characteristics of $\mathrm{gHH} 1, \mathrm{gHH} 2, \mathrm{gHH} 3, \mathrm{gHH} 5$, and $\mathrm{gBH} 1$ peptides}

The structural characteristics of the five peptides that demonstrated protective effects in the cell and embryo infectivity assays were examined. Firstly, MS spectrometry showed that the molecular masses of gHH1, gHH2, gHH3, gHH5, and gBH1 were 3184, 3623, 3795, 3002 and $3303 \mathrm{Da}$, respectively. To investigate the structures of these peptides, gel filtration (GF) and circular dichroism (CD) spectroscopy analyses were performed. These results demonstrated that the majority of the peptides transitioned to the oligomeric state in the polar environments of Tris- $\mathrm{HCl}$ and lipidic solutions with 2,2,2 trifluoroethanol (TFE). Specifically, GF chromatography of gHH2 demonstrated the formation of a homodimeric structure with a molecular mass of about $7.2 \mathrm{kDa}$ in aqueous solution. CD spectroscopy of gHH2 showed that the peptide adopts a $\beta$-sheet conformation in aqueous solution, and this tendency towards $\beta$-sheet formation becomes more obvious in a TFE solution. GF chromatography of gHH5 revealed a molecular mass of $9.1 \mathrm{kDa}$, suggesting the formation of a homotrimeric structure in polar environments. Analysis of gHH5

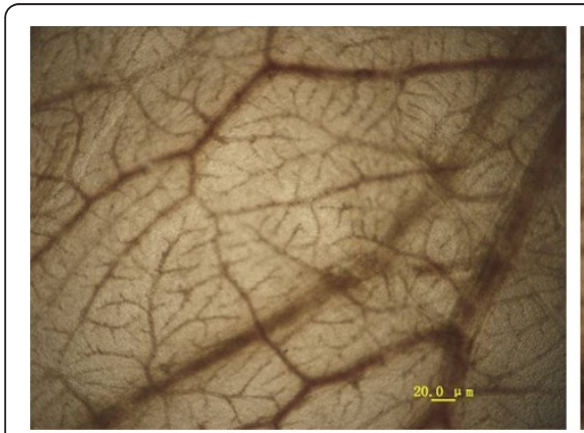

(a)

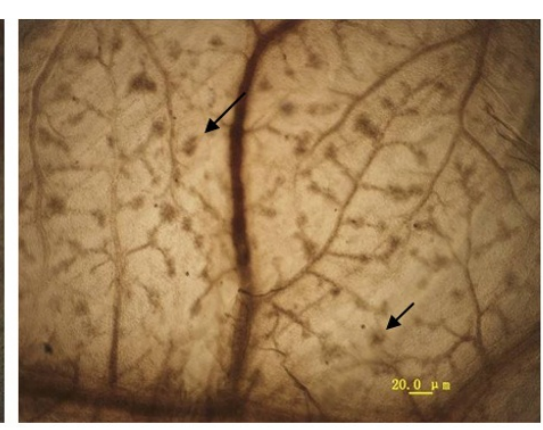

lesion formation

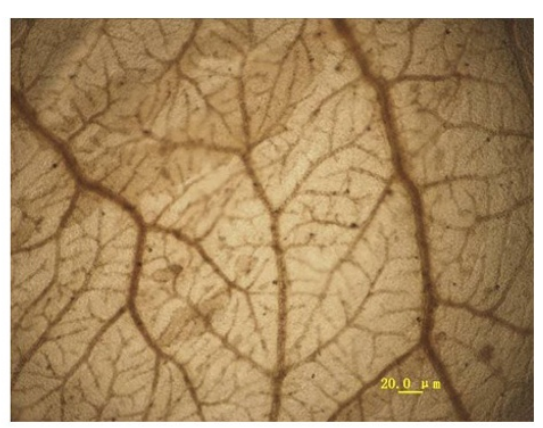

lesion formation inhibition

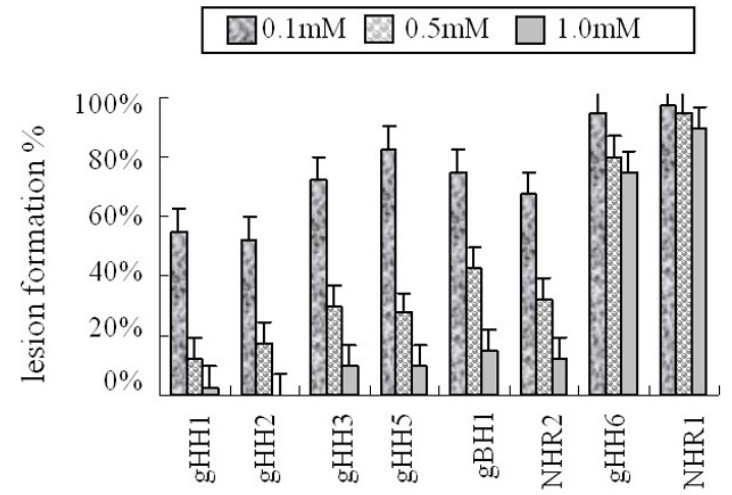

(b) co-treatment

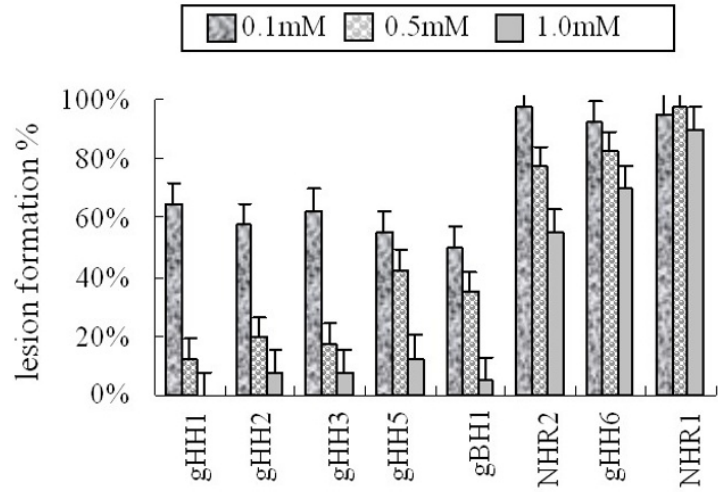

(c) post-treatment

Figure 4 Pathological reduction by treatment of MDV with peptides in chicken embryos. (a) Photos show pathological changes induced by treatment of virus with or without peptides from chicken embryos (at $10 \times 20$ magnification, arrows indicate gray lesions). These representative images show normal membrane (no treatment), 100\% lesion formation (infected by $10^{3}$ pfu of MDV without peptides) and $0 \%$ lesion formation ( $10^{3} \mathrm{pfu}$ of MDV with $1.0 \mathrm{mM} \mathrm{gHH2}$ in co-treatment assay, i.e., $100 \%$ lesion formation inhibition), respectively. (b and c) The infectivity rates (proportion of lesion formation) in the presence of different peptides at various concentrations $(0.1,0.5,1.0 \mathrm{mM})$ for co-treatment (Fig. 4b) and post-treatment (Fig. 4c) assays. Peptides gHH1, gHH2, gHH3, gHH5, gBH1, NHR2, gHH6, and NHR1 are shown from left to right, respectively. 
revealed a conformational change from a random coiled structure to a more obvious $\alpha$-helical structure when the peptide was transferred from a polar environment to membrane interfaces using aqueous mixtures of TFE, suggesting the formation of potential higher-order oligomers in lipidic solutions. These results are presented in Figures 5 and 6.

For gHH1, gBH1, and gHH3, which share a similar $\alpha$ helical secondary structure, GF chromatography and CD spectroscopy were performed under the same experimental conditions. GF chromatography of gHH1 demonstrates the formation of a homotetrameric structure with a molecular mass of about $12.1 \mathrm{kDa}$, matching the sum of four peptides. The gBH1 peptide forms a homotrimeric structure with a molecular mass of 10.7 $\mathrm{kDa}$, which is approximately equal to the sum of three molecules; gHH3 adopts a monomer formation with a molecular mass of $3.8 \mathrm{kDa}$ (see Figure 5). Results of $\mathrm{CD}$ analysis of gHH1, gHH3, and $\mathrm{gBH} 1$ show that all three peptides adopt a standard $\alpha$-helical conformation with double minima at $208 \mathrm{~nm}$ and $222 \mathrm{~nm}$ in a PBS-buffered solution, and the tendency to form $\alpha$-helices is clearer in the presence of TFE (see Figure 6).

\section{Discussion}

In this study, eleven potential HR regions of MDV $\mathrm{gH}$ and $\mathrm{gB}$ were identified using GOR bio-software. These regions overlap with some $\alpha$-helix-enriched regions, including gHH1, gHH3 and gBH1, and with hydrophobic regions, including gHH2 and gBH1 (data not shown). MDV glycoproteins have more HR regions than herpes simplex virus type $1(\mathrm{HSV}-1)$ and human

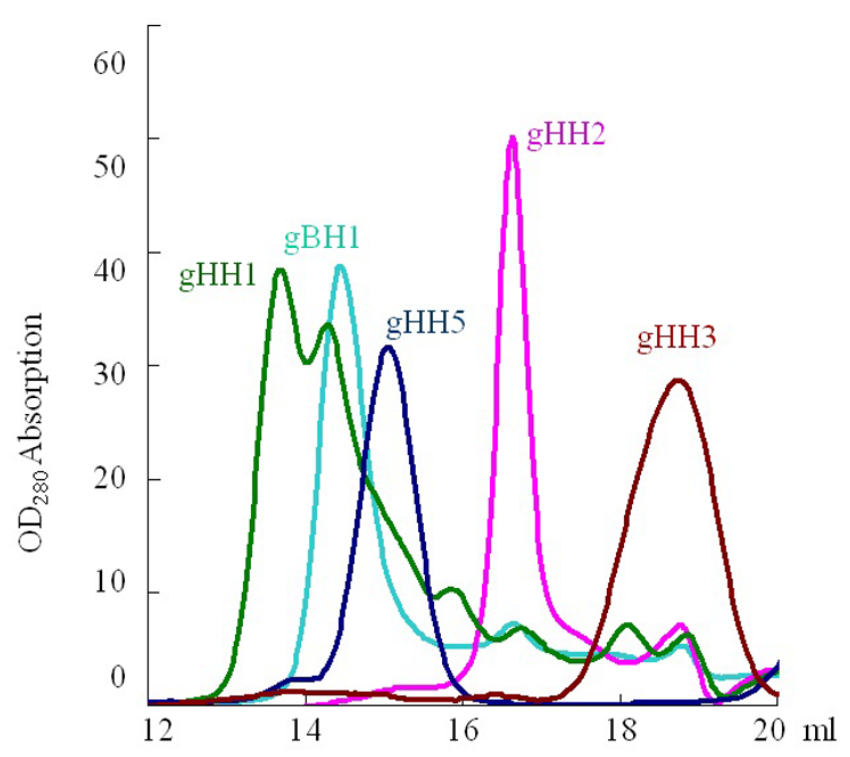

\begin{tabular}{ccccc}
\hline Peptides & Sequence & $\begin{array}{c}\text { MW of } \\
\text { monomer }\end{array}$ & $\begin{array}{c}\text { MW of } \\
\text { polymer }\end{array}$ & Oligomeric state \\
\hline gHH1 & HMNASDMEIKSYINMIESVEESSNYDF & $3184 \mathrm{Da}$ & $12.1 \mathrm{kDa}$ & $\mathbf{4}$ (tetramer) \\
gHH2 & VVTTRLFMSLVASVRNAFQSGYISFDEIKTE & $3623 \mathrm{Da}$ & $7.2 \mathrm{kDa}$ & 2 (dimer) \\
gHH3 & NADIIKSLIRKTIINASKNTASLSILQHLYVLRS & $3795 \mathrm{Da}$ & $3.8 \mathrm{kDa}$ & $\mathbf{1}$ (monomer) \\
gHH5 & CTEEHIVATELVIQEMYIKINVKNSP & $3002 \mathrm{Da}$ & $9.1 \mathrm{kDa}$ & $\mathbf{3}$ (trimer) \\
gBH1 & RIILGQCIKREAEAAIEQIFRTKYNDSH & $3303 \mathrm{Da}$ & $\mathbf{1 0 . 7} \mathrm{kDa}$ & $\mathbf{3 \text { (trimer) }}$ \\
\hline
\end{tabular}

Figure $5 \mathrm{GF}$ results and structural analyses of five peptides. (top) GF analysis of peptides. The purified peptides were loaded onto the Superdex G75 column in a buffer solution of $20 \mathrm{mM}$ Tris-HCl, pH 8.0. The peak molecular mass was estimated by comparison with the protein standards running on the same column. The clear peak of gHH1 occurred at about $12.1 \mathrm{kDa}$. This molecular mass matches the approximate sum of four molecules, indicating the formation of the homotetrameric structure. The peak of $\mathrm{gHH} 2$ occurred at about $7.2 \mathrm{kDa}$, indicating the formation of the homodimeric structure. The peak of $\mathrm{gHH} 3$ occurred at about $3.8 \mathrm{kDa}$, indicating the monomeric state. The peak of $\mathrm{gHH} 5$ occurred at about $9.1 \mathrm{kDa}$, indicating the formation of the homotrimeric structure. The peak of $\mathrm{gBH} 1$ occurred at about $10.7 \mathrm{kDa}$, indicating the formation of the homotrimeric structure. (bottom) Sequences and calculated oligomeric states of $\mathrm{gHH} 1, \mathrm{gHH} 2, \mathrm{gHH} 3, \mathrm{gHH} 5$, and gBH1 in aqueous solution. 

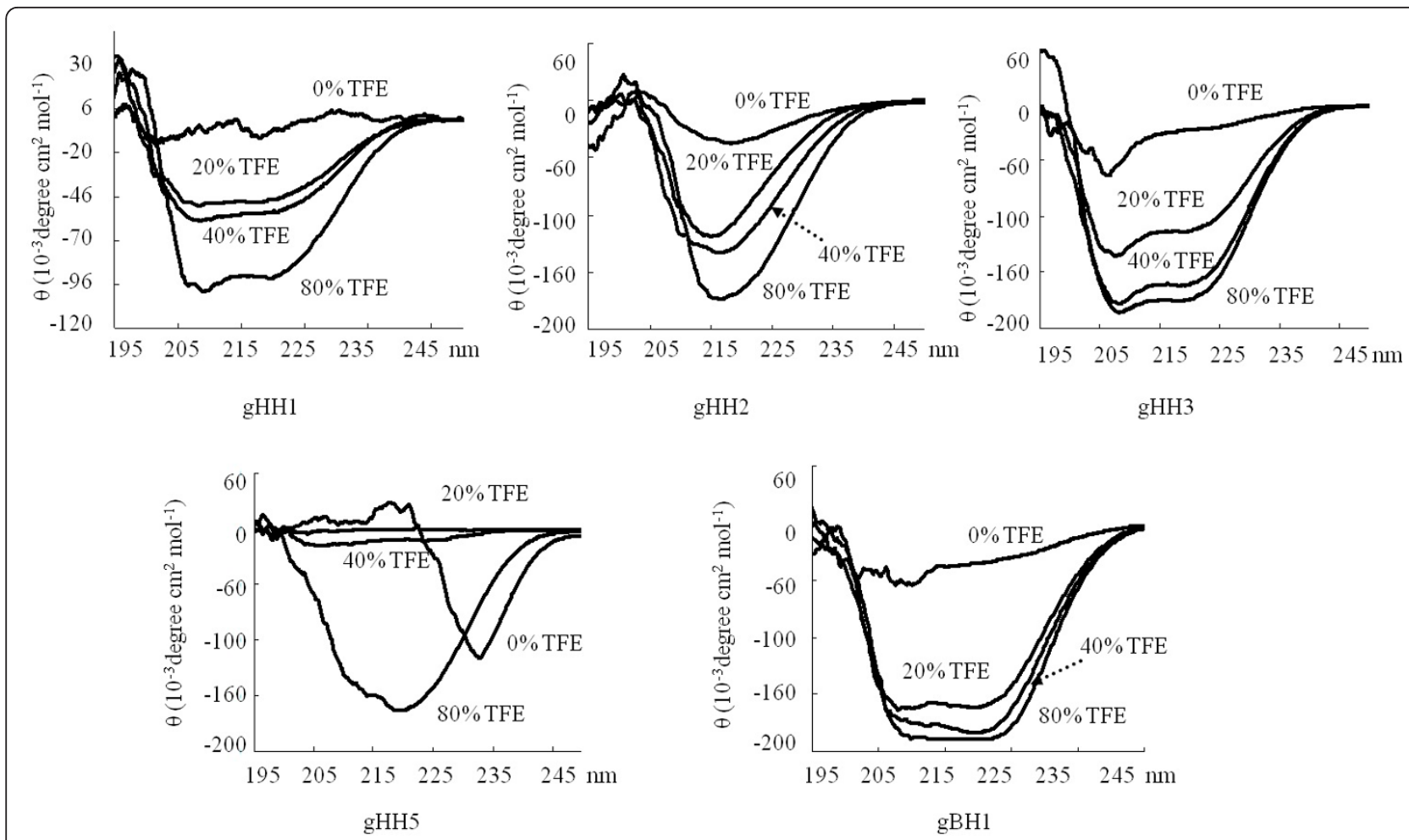

Figure $6 \mathrm{CD}$ spectroscopy analyses of peptides. $\mathrm{CD}$ spectroscopic results of $\mathrm{gHH} 1, \mathrm{gHH} 2, \mathrm{gHH} 3$, gHH5 and gBH1 in PBS solution with $0 \%$, $20 \%, 40 \%, 80 \% \mathrm{TEF}$, respectively. The $\mathrm{gHH1}$, gHH3 and gBH1 peptides adopted a standard $\alpha$-helical conformation with double minima at 208 $\mathrm{nm}$ and $222 \mathrm{~nm}$ in a PBS-buffered solution and remained practically unaltered in the presence of TFE. CD analysis of gHH2 showed that the peptide adopted a $\beta$-sheet conformation in buffer solution, and its CD spectra remained practically unaltered in TFE solution. gHH5 had a structural change from random coil to $\alpha$-helical structure when the peptide was transferred from a polar environment to membrane interfaces using aqueous mixtures of TFE.

cytomegalovirus (HCMV), which have only two HR regions in $\mathrm{gH}$ or $\mathrm{gB}[11,12]$. Furthermore, five peptides (gHH1, gHH2, gHH3, gHH5, and gBH1) showed potent antiviral activity in a plaque formation assay using MDV-infected CEFs and were considered for further analysis (see Figure 2c). The plaque formation studies also demonstrated that the most active peptide, gHH1, was effective both against viral entry and after virus entry, while gHH2 was most effective in the virus pretreatment assay (see Figure 2d). The inhibitory activity of the peptides may have occurred via the peptides associating with glycoproteins $\mathrm{gH}$ or gB to block the conformational changes of these glycoproteins that are crucial for fusion; it is also possible that these peptides may inhibit glycoprotein binding to receptors $[13,23]$.

We used CEF-associated MDV instead of cell-free MDV in cell infectivity and embryo assays due to the need for consistent treatment in terms of virus titre at different times [24]. Ever since Woodruff and Goodpasture [25] first introduced the technique of cultivating fowlpox virus on the CAMs of a chicken embryo, this method has been widely used in studies of virus isolation (herpesvirus) and tissue invasion by viral transformed cells and been considered as a model system to screen drugs $[26,27]$. Due to the effect of serially passaged MDV on inducing varied lesions on CAMs, we used the same passage of CEF-associated MDV to study lesion formation and reduction after peptide treatment [28]. In addition, within a range of 50 to 80 lesions per membrane, a linear relationship exists between the number of lesions and the infecting virus dilution. Therefore, $10^{3} \mathrm{pfu}$ MDV that formed a mean number of 63 lesions was selected for use in this assay. In vivo assays may be performed by counting the number of lesions appearing on CAMs after a few days (i.e., 5-6 days) after their direct in vivo (DIO) inoculation [29] or 10-14 days after inoculation of yolk sacs of 9-10-day-old eggs [30,31]. In our study, infective inoculum was inoculated into yolk sacs of 6-7-day-old chicken embryos. After 9 days of additional incubation, surviving embryos were monitored for lesion formation. Although the egg still alive until day 10-13 after infection, the lesion size on CAMs was sometimes inconsistent (e.g., there was separation into large and small lesions). As a result, we used 9 days post-infection as a constant observation time, which gave the results considerable precision. The 
tested peptides showed potent antiviral activity in the embryo assay, and both gHH1 and gHH2 were very effective in co-treatment and post-treatment assays at a concentration of $1.0 \mathrm{mM}$ (see Figure 4). Further experiments will examine the infection of maternal antibodyfree 1-day old chickens (SPF chickens) with a pathogenic strain of MDV with or without peptides to study the role of these peptides on the pathogenesis of MDV.

Much established evidence has shown that the HR2 regions of fusion glycoproteins from enveloped viruses have potent and specific antiviral activities [1]. Our previous research demonstrated that the HR2 from NDV (i. e., avian paramyxovirus-1, APMV-1) is a specific inhibitor of NDV membrane fusion that has no cross-inhibitory activity against APMV-2 [32]. Some reports on the $\mathrm{HR}$ region of bovine herpesvirus type 1 (BoHV-1) have shown infection inhibition activity, which was obtained not only with other herpesviruses but also partly with NDV [33]. In this study, we tested a highly effective inhibitor of NDV infection for its ability to inhibit the infectivity of the unrelated MDV. The results of cell infectivity and embryo assays indicated that NDVHR2 exerted effects on MDV in the specific stage of virus entry (i.e., in cell pre-treatment and embryo co-treatment assays), suggesting a potential cross-inhibitory effect of NDV HR2 in MDV infection. In addition, NDVHR1 did not exert any effect on MDV infection, supporting the specificity of the antiviral effect of the MDV-derived peptides in this paper (see Figures 2 and 4).

We further studied the structures of the peptides used in this study. The three-dimensional (3-D) structure of HSV-2 gH shows three distinct domains: the N-terminal domain that binds gL (H1 domain), the central helical domain (H2 domain) and the C-terminal $\beta$-sandwich domain (H3 domain). Six MDV gH-derived peptides (gHH1, H2, H3, H4, H5, and H6) are within the $\mathrm{H} 2$ domain, which is globular and mostly helical. The $\mathrm{H} 2$ domain contains thirteen $\alpha$-helices and three short $3_{10}$ helices. In addition to the helices, this domain has a $\beta 12$ strand that participates in a six-stranded $\beta$-sheet within the $\mathrm{H} 1 \mathrm{~B}$ subdomain and a short $\beta 11$ strand that makes a small antiparallel $\beta$-sheet with the $\beta 4$ strand of the H1B subdomain [5]. In the current study, results of GF and $\mathrm{CD}$ analyses showed that MDV-gHH1 adopts a homotetrameric structure with a standard $\alpha$-helical conformation, consistent with the 3-D result and this tendency to form $\alpha$-helices is more obvious in the presence of TFE. The ratio of ellipticities at 222 and $208 \mathrm{~nm}$ can be utilized to distinguish between the monomeric and oligomeric states of helices [13]. When the $\theta 222 / \theta 208$ ratio is approximately 0.8 , the peptide is in its monomeric state, and when this ratio exceeds 1.0 , the peptide is in its oligomeric state. The CD data from MDV-
gHH1 reveals that gHH1 undergoes a conformational change from the oligomeric state to a monomer/oligomer equilibrium, following which it shifts towards the monomeric state with increasing concentrations of TFE (see Figures 5 and 6). Furthermore, amino-acid alignment analysis was employed to compare the corresponding domains of MDV-gHH1 with those in other $\alpha$-herpesviruses. No significant antiviral activity was found in published reports. The MDV-gHH2 has a homodimeric structure and adopts a $\beta$-sheet conformation in aqueous solution, and this $\beta$-sheet tendency is more obvious in TFE solution, as highlighted by the fact that MDV-gHH2 has a more obvious tendency to oligomerize in membrane interfaces (see Figures 5 and 6). MDV-gHH2 may be important as a binding site for glycoprotein receptors, given its potent antiviral activity, its performance in the virus pre-treatment assay, and its high propensity for interfacial hydrophobicity. The secondary structure of gHH2 is similar to that of the HSV1 internal fusion peptide (IFP) region (a.a. 377 to 397), from which the ability to partition into membranes and aggregate within them arises [16]. However, the domains of HSV-1 a.a. 381-420 which correspond to MDV-gHH2 did not show any significant antiviral activity [23]. Two HSV-1 peptides, a.a. 493 to 512 and a.a. 626 to 644 of HSV-1 gH, are homologous to MDV-gHH4 and MDVgHH6, respectively. Both peptides showed highly antiviral activity and exhibited membranotropic characteristics [23,34]. However, MDV-gHH4 and MDV-gHH6 did not show potent antiviral activity in our study. It is worth noting that the gHH1, H2, H4, and $\mathrm{H} 6$ peptides of MDV gH showed different antiviral functions from the corresponding domains derived from $\mathrm{HSV}-1 \mathrm{gH}$. In fact, only $23 \%$ residue identities exist between MDV gH and HSV-2 gH, and no existing analytical tools can predict the structure of MDV $\mathrm{gH}$ according to the resolved 3-D structure of HSV-2 $\mathrm{gH}$.

It has been established that both the HR1 (a.a. 444 to 479) and HR2 (a.a. 542 to 582) domains of HSV-1 gH show potent antiviral activity in cell infectivity assays [11]. These domains were recently studied by Chowdary et al. using x-ray crystallography. These authors' results indicated that the pre-fusion structure of HSV-2 gH did not reveal any domains with heptad repeat (HR) characteristics [5]. The trimeric hairpin bundle, which was suggested to be characteristic of the post-fusion form of class I and class III fusogens, is absent from the $\mathrm{gH}$ structure, although these two domains can form helical bundles. Given that $\mathrm{gH}$ appears to be able to mediate cell-cell fusion in some herpesviruses, we cannot exclude the possibility that $\mathrm{gH}$ has some intrinsic fusogenic properties $[10-16,34]$. It is possible that the conformation of $\mathrm{gH}$ could change during the fusion process or viral entry to expose heptad repeats not observed in 
the pre-fusion structure. The results of $\mathrm{CD}$ analysis of MDV-gHH3 (homologous to HR1 of HSV-1 gH) in the present study showed that the peptide adopts a standard $\alpha$-helical conformation and that there was no effect of polarity on the monomeric state when the peptide was transferred from polar to non-polar membrane environments, similar to the GF result in aqueous solution. MDV-gHH5 (homologous to HR2 of HSV-1 gH) revealed the formation of a homotrimeric structure in polar environments and the formation of $\alpha$-helical structure in lipidic solutions (see Figures 5 and 6). More importantly, our study revealed that both MDV-gHH3 and MDV-gHH5 show potent antiviral activity, not only in plaque formation assays (in vitro) but also in embryo assays (in vivo) (see Figures 2 and 4), further supporting the idea that these peptides have fusogenic properties involved in the viral entry process.

Based on the gB crystal structure, the gB trimer can be divided into six distinct structural domains, and four functional regions (FR) have been defined based on the mapping of anti-gB neutralizing MAbs to the crystal structure [4]. In the current study, the MDV-gBH1 in domain II adopted an $\alpha$-helical conformation in $20 \%$ TFE solution with the monomer/oligomer equilibrium shifting toward the oligomeric state in $40 \%$ TFE. At higher concentration of TFE of $80 \%$, the ratio of ellipticities at 222 and $208 \mathrm{~nm}$ decreases to approximately 1.0, indicating a monomer/oligomer equilibrium state (see Figures 5 and 6). HSV-1 gB389-398, which is homologous to $\mathrm{gBH} 1$, is unable to induce lipid mixing in this assay condition and did not significantly inhibit infection in another study [15]. However, MDV-gBH1 showed higher antiviral activity, not only in vitro but also in vivo. As for other gB-derived peptides, a recent study by Atanasiu et al. suggested that FR2 in domain II (the main epitopes of FR2 lies within residues 454 to 473 homologous to gBH2) plays a critical role in the interaction between $\mathrm{gB}$ and $\mathrm{gH}$, and the $\mathrm{gB}$ binding site is considered to be an attractive target for antiviral design [35]. In our study, MDV-gBH2 did not show significant antiviral activity. This result suggests that residues involved in the interaction between $\mathrm{gB}$ and $\mathrm{gH}$ are not essential for membrane fusion. In fact, the predicted MDV-gBH2 structure is quite different from that of HSV-1 gB (see Figure 7). It is worth noting that HR1 (a. a. 477 to 510 ) and HR2 (a.a. 696 to 724 ) from gB of bovine herpesvirus type 1 (BoHV-1) have been studied [33], and only the former consistently inhibited virus replication. In the current study, a.a. 467 to 500 (homologous to HR1 of BoHV-1gB, data not shown) in domain III, MDV-gBH3 in domain IV and MDV-gBH4 (homologous to HR2 of BoHV-1gB) in domain $\mathrm{V}$ did not show meaningful antiviral activity. MDV gB-derived peptides clearly showed different antiviral functions from the corresponding domains derived from gB peptides of other $\alpha$-herpesviruses. Figure 7 (right) schematically presents the locations of the potential inhibitory peptides on the MDV gB ectodomain.

Membrane fusion is an important step in enveloped virus entry into host cells. The present study on the antiviral activity of MDV-derived peptides that are involved in the viral entry process reveals viral entry mechanisms. These peptides may be also useful as small-molecule antiviral inhibitors. It is notable that some peptides were able to block viral infection at a post-attachment entry step, suggesting that the peptides would likely be useful as oral preventive agents or as microbicides. Further studies are needed to better define the precise mechanisms of inhibition of these peptides and the specific nature and location of their interactions with viral targets. Additional issues concerning the similarities and differences between the membrane fusion mechanisms of MDV and other $\alpha$-herpesviruses should also be addressed.

\section{Methods}

\section{Prediction and analysis of fusogenic regions}

The combined use of biological software prompted us to analyse the different domains of gH (GenBank Accession No. AAL37975) and gB (GenBank Accession No. AAM97699) of MDV strain RB1B in detail for potential membrane fusion-related regions. Biological software package ExPASy-Coils http://www.ch.embnet.org/software/coils/COILS_doc.html, which has been successfully used to analyse a number of viral fusion proteins, was used to study coiled-coils (see Figure 1). We chose the ExPASy-tools program (GOR software, http://www.ch. embnet.org/, as it was designed specifically to analyse secondary structures. Hydropathy plots corresponding to the sequences of MDV gH and $\mathrm{gB}$ were obtained using TMpred (ExPASy, Swiss Institute of Bioinformatics, http://www.ch.embnet.org and Membrane Protein eXplorer (MpeX, Stephen White laboratory, http:// blanco.biomol.uci.edu/mpex). In particular, hydropathy plots were obtained using the hydropathy index of Kyte and Doolittle and the interfacial hydrophobicity scales of Wimley and White for individual residues.

The peptides from MDV gH, identified as $\mathrm{H} 1, \mathrm{H} 2, \mathrm{H} 3$, $\mathrm{H} 4, \mathrm{H} 5$, and $\mathrm{H} 6$, are located at amino acid (a.a.) residues 277 to 303,331 to 362,396 to 429,434 to 467,508 to 533 , and 576 to 604 , respectively. The peptides from MDV gB, identified as $\mathrm{H} 1, \mathrm{H} 2, \mathrm{H} 3, \mathrm{H} 4$, and $\mathrm{H} 5$, are located at a.a. residues 340 to 367,406 to 443,560 to 590, 657 to 686 , and 775 to 883 , respectively.

\section{Primer design and gene construction}

All genes were constructed using the bridging PCR method and cloned into the GST fusion expression 


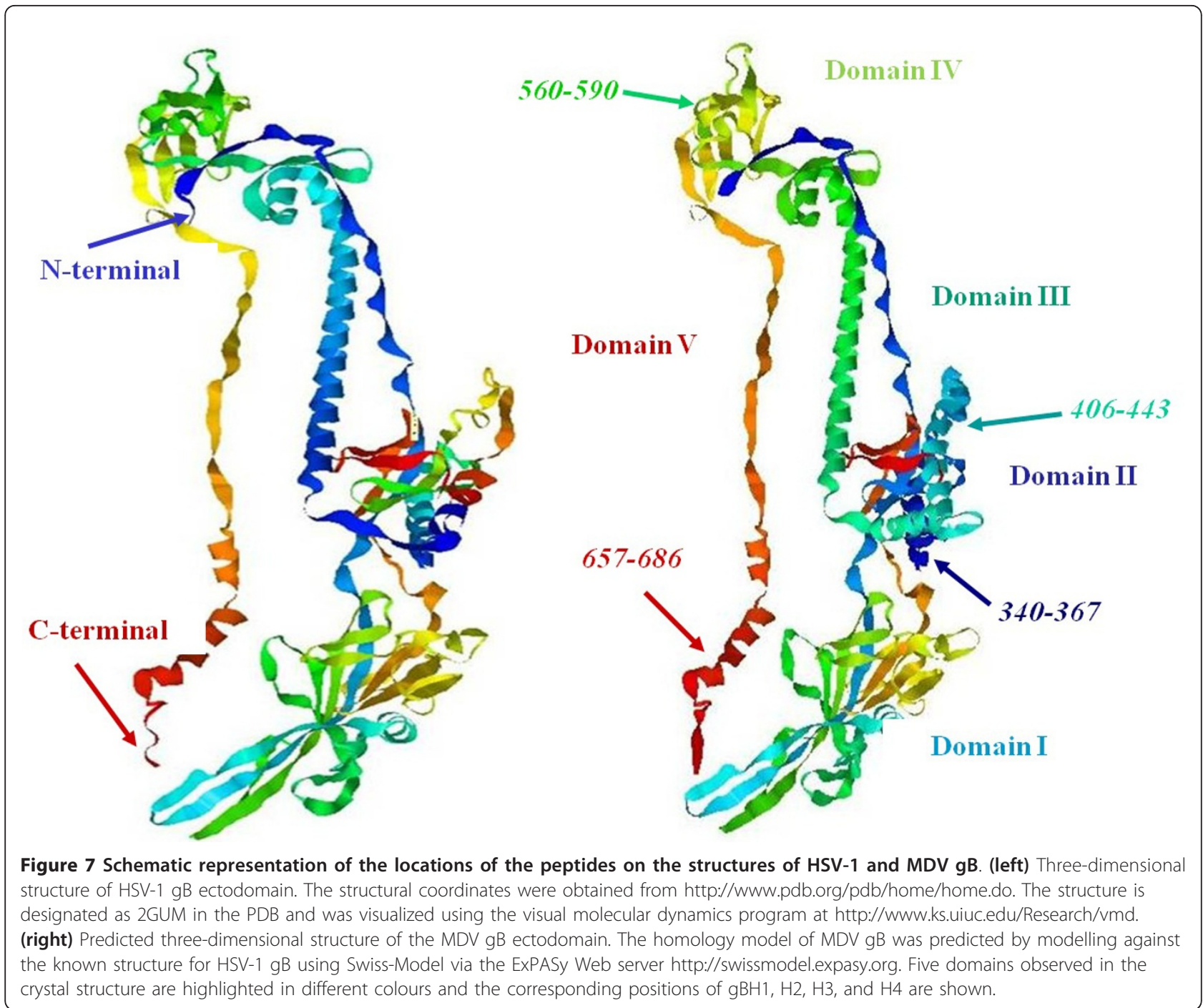

vector pGEX-6P-I at the BamHI-XhoI restriction sites where there is a rhinovirus $3 \mathrm{C}$ protease cleavage site for the fusion protein (as in the commercial PreScission ${ }^{\mathrm{TM}}$ protease cleavage site). The positive plasmids were verified by direct DNA sequencing.

\section{Protein expression and purification}

Escherichia coli strain Ros, transformed with the recombinant pGEX-6p-I plasmid, was grown at $37^{\circ} \mathrm{C}$ in $2 \times$ YTA to an optical density of 0.8-1.0 (OD at $590 \mathrm{~nm}$ ) before being induced with $1 \mathrm{mM}$ IPTG for 4 hours. Bacterial cells were harvested and lysed by sonication in PBS (pH 7.3). Triton X-100 was then added to a final concentration of $1 \%$ and the lysate was incubated for 30 min at $0^{\circ} \mathrm{C}$. The clarified supernatants were passed through a Glutathione-Sepharose 4B column. The GST fusion protein-bound column was washed with over 10 column volumes of PBS and eluted with 3 column volumes of reduced glutathione. The GST fusion proteins were then cleaved by GST fusion rhinovirus 3C protease at $5^{\circ} \mathrm{C}$ for 16 hours in a $50 \mathrm{mM}$ Tris- $\mathrm{HCl}$ buffer, $\mathrm{pH}$ 7.0. The cleaved proteins were then purified by affinity filtration (with the Glutathione-Sepharose 4B column) following which the column-unbound protein was extracted and concentrated by ultrafiltration with 3K membranes (Millipore). The resultant protein was dialyzed against PBS, reduced to a proper concentration by ultrafiltration and stored at $-70^{\circ} \mathrm{C}$ for further analysis. GST fusion proteins and cleaved proteins were analysed by $15 \%$ tricine SDS-PAGE.

\section{Preparation of MDV stock}

Primary chicken embryo fibroblasts (CEFs) were grown in DMEM supplemented with $10 \%$ foetal calf serum (FCS) and were allowed to attach overnight. CEF-associated MDV strain RB1B (from Shandong Agriculture 
University, has been passaged multiple times in primary CEFs) was incubated for 2 hours at $37^{\circ} \mathrm{C}$. Following incubation, the virus samples on the cells were replaced with DMEM supplemented with $2 \%$ FCS and the cultures were incubated for another 5 days [24,36]. Consistent and uniform plaques were observed and counted under an Olympus microscope and images were captured using DP Controller software. CEF-associated MDV from the same passage at $2 \times 10^{4}$ plaque forming units (pfu) was used in both cell infectivity and chicken egg assays in this study.

\section{Effect of the peptides on plaque formation}

All of the peptides were dissolved in DMEM without FCS and used at a range of concentrations. For the antiviral activities of peptides in the co-treatment assay, 100 pfu of MDV was incubated with the peptide at different concentrations for 2 hours at $37^{\circ} \mathrm{C}$. A no-peptide sample control was also prepared and this sample was regarded as $100 \%$ plaque formation. Following incubation, the virus-peptide mixtures on the cells were replaced with DMEM supplemented with 2\% FCS and the cultures were incubated for 5 days. At the end of this incubation, $50 \%$ inhibitory concentrations $\left(\mathrm{IC}_{50}\right)$ values were calculated.

To assess the effects of peptides with $\mathrm{IC}_{50}$ values below $12 \mu \mathrm{M}$ on the inhibition of MDV infectivity, four different methods $[13,23]$ of treating cell monolayers were used: 1) Virus pre-treatment - virus was incubated in the presence of peptides at $25 \mu \mathrm{M}$ for 1 hour at $37^{\circ} \mathrm{C}$ and was then titrated onto cell monolayers; 2) Cell pretreatment - cells were incubated with peptides for 30 minutes at $4^{\circ} \mathrm{C}$. Peptides were removed, and cells were washed with PBS. Following this treatment, the cells were infected with MDV; 3) Co-treatment - the cells were incubated peptides in the presence of viral inoculum for 1 hour at $37^{\circ} \mathrm{C}$; and 4) Post-treatment - cell monolayers were infected with virus for 45 minute at $37^{\circ} \mathrm{C}$. The peptides were then added to the inoculum, followed by an additional 30 minute incubation at $37^{\circ} \mathrm{C}$. Monolayers were incubated for 5 days at $37^{\circ} \mathrm{C}$ in DMEM supplemented with $2 \%$ FCS. The ratio of plaque counts to the no-peptide sample control is reported as the percentage of plaque formation (by arithmetic conversion of the mean percent plaque formation). Results are expressed as the average of triplicates \pm the standard deviation and all experiments were conducted in parallel with each peptides and non-specific peptides.

\section{LDH assay for toxicity analysis}

Peptide cytotoxicity was measured using the lactate dehydrogenase (LDH) assay. This assay was performed according to the manufacturer's instructions using a commercial cytotoxicity detection kit (Roche).

\section{Virus-yield reduction assay in chicken embryos}

Briefly, $1 \times 10^{3} \mathrm{pfu}$ of CEF-associated MDV, was injected into yolk sacs of 6-7-day-old embryonating specific-pathogen free (SPF) chicken eggs. After 9 days of additional incubation, surviving embryos were chilled overnight at $4^{\circ} \mathrm{C}$ and observed for lesion formation.

In the co-treatment protocol, a mixture of the MDV inoculum $\left(1 \times 10^{3} \mathrm{pfu}\right)$ with various concentrations of peptide $(0.1,0.5,1.0 \mathrm{mM})$ in $60 \mu \mathrm{l}$ of solution was injected into the yolk sacs of chicken eggs and incubated at $37^{\circ} \mathrm{C}$ for 9 days. For post-treatment assays, the yolk sacs were infected with virus for 1.5 hours at $37^{\circ} \mathrm{C}$ and then peptides were administered over a range of concentrations for 9 days. The chorioallantoic membranes (CAMs) at day 9 post-incubation were fixed in 10\% buffered formalin. Lesions (pox) were observed and counted under an Olympus microscope, and lesion images were captured using DP Controller software. The ratio of lesion counts to the no-peptide sample control is presented as the percentage of infection (by arithmetic conversion of the mean percent lesion formation). Results are expressed as the average of triplicates \pm the standard deviation and all experiments were conducted in parallel with each peptides and non-specific peptides. Five embryos were used in each experiment to generate small standard errors in the assay.

\section{Mass spectrometry (MS) analyses}

All of the purified cleaved peptides were resolved in a $20 \mathrm{mM}$ Tris- $\mathrm{HCl}, \mathrm{pH} 8.0$ buffer and then analysed using the Bruker Daltonics Biflex III MALDI-TOF Mass Spectrometer to ascertain the molecular masses of the peptides.

\section{Gel filtration (GF) analyses}

The purified cleaved peptides were loaded onto the Superdex G75 column in a solution buffer of $20 \mathrm{mM}$ Tris- $\mathrm{HCl}, \mathrm{pH}$ 8.0. The peak molecular mass was estimated by comparison with protein standards running on the same column. The peak fractions were collected and analysed by $15 \%$ SDS-PAGE. The analytical column was calibrated using a series of individual runs of standard molecular mass proteins as markers including bovine serum albumin $(68 \mathrm{kDa})$, egg white albumin $(43$ $\mathrm{kDa})$, ribose nucleotidase $(13.7 \mathrm{kDa})$, aprotinin $(6.5$ $\mathrm{kDa})$, antimicrobial peptides $(5 \mathrm{kDa})$, and vitamin $\mathrm{B} 12$ (1.4 kDa).

\section{Circular dichroism (CD) spectroscopy analyses}

The purified, cleaved peptides were dissolved in $10 \mu \mathrm{M}$ PBS, pH 7.4 with $20 \%, 40 \%$, or $80 \% 2,2,2$ trifluoroethanol (TFE). The wavelength-dependence of molar ellipticity $[\theta]$ was monitored at $25^{\circ} \mathrm{C}$ as the average of eight scans in a spectropolarimeter (Model J-710) equipped 
with a thermoelectric temperature controller. The TFE solution was obtained from Fluka (Sigma-Aldrich, Milan, Italy) and was prepared using distilled water. The buffers were also filtered in a vacuum pump system using $0.2 \mu \mathrm{m}$ pore membrane filters. TFE is widely used in conformational studies because it promotes intramolecular hydrogen bonds in spite of intermolecular interactions with water molecules. Moreover, as TFE lowers the polarity of the solution, the environmental changes explored by the peptides resemble those of the native sequences during the membrane fusion process [13].

\section{Acknowledgements}

This work was supported by the Foundation for the Authors of National Excellent Doctoral Dissertations of PR China (FANEDD) (2006079) and supported by the Chinese Universities Scientific Fund (2009JS10). We thank Prof. Klaus Osterrieder at Free University of Berlin for invaluable material support. We thank also Prof. Zhi-Zhong Cui at Shandong Agricultural University for generously supplying samples of MDV strain RB1B.

\section{Authors' contributions}

XW conceived of the study, performed a design of experiments and the biosoftware analysis. XC carried out the structural characteristics studies, participated in plaque and lesion formation assays. MW participated in statistical analysis and coordination. All authors read and approved the final manuscript.

\section{Competing interests}

The authors declare that they have no competing interests.

Received: 14 January 2011 Accepted: 25 April 2011

Published: 25 April 2011

\section{References}

1. Eckert DM, Kim PS: Mechanisms of viral membrane fusion and its inhibition. Ann Rev Biochem 2001, 70:777-810.

2. Heldwein EE, Krummenacher C: Entry of herpesviruses into mammalian cells. Cell Mol Life Sci 2008, 65:1653-68.

3. Backovic M, Jardetzky TS: Class III viral membrane fusion proteins. Curr Opin Struct Biol 2009, 19:189-96.

4. Heldwein EE, Lou H, Bender FC, Cohen GH, Eisenberg RJ, Harrison SC: Crystal structure of glycoprotein B from herpes simplex virus 1. Science 2006, 313:217-20.

5. Chowdary TK, Cairns TM, Atanasiu D, Cohen GH, Eisenberg RJ, Heldwein EE: Crystal structure of the conserved herpesvirus fusion regulator complex gH-gL. Nat Struct Mol Biol 2010, 17:882-8.

6. Campadelli-Fiume G, Amasio M, Avitabile E, Cerretani A, Forghieri C, Gianni T, Menotti L: The multipartite system that mediates entry of herpes simplex virus into the cell. Rev Med Virol 2007, 17:313-26.

7. Gianni T, Forghieri C, Campadelli-Fiume G: The herpesvirus glycoproteins $B$ and $H . L$ are sequentially recruited to the receptor-bound $\mathrm{gD}$ to effect membrane fusion at virus entry. Proc Natl Acad Sci USA 2007, 104:3668-73.

8. Kirschner AN, Omerovic J, Popov B, Longnecker RL, Jadetzky TS: Soluble Epstein-Barr virus glycoproteins $\mathrm{gH}, \mathrm{gL}$, and gp42 form a 1:1:1 stable complex that acts like soluble gp42 in B-cell fusion but not in epithelial cell fusion. J Virol 2006, 80:9444-9454.

9. Ryckman BJ, Rainish BL, Chase MC: Characterization of the human cytomegalovirus $\mathrm{gH} / \mathrm{gL} / \mathrm{UL} 128-31$ complex that mediates entry into epithelial and endothelial cells. J Virol 2008, 82:60-70.

10. Galdiero S, Falanga A, Vitiello M, Browne H, Pedone C, Galdiero M: Fusogenic domains in herpes simplex virus type 1 glycoptein $\mathrm{H}$. J Boil Chem 2005, 280:28632-43.

11. Galdiero S, Vitiello M, D'Isanto M, Falanga A, CollinS C, Raieta K, Pedone C, Browne $\mathrm{H}$, Galdiero M: Analysis of synthetic peptides from heptad-repeat domains of herpes simplex virus type 1 glycoproteins $\mathrm{H}$ and $\mathrm{B}$. J Gen Virol 2006, 87:1085-97.
12. Lopper $\mathrm{M}$, Compton $\mathrm{T}$ : Coiled-coil domains in glycoproteins $\mathrm{B}$ and $\mathrm{H}$ are involved in human cytomegalovirus membrane fusion. J Virol 2004, 78:8333-41.

13. Akkarawongsa R, Pocaro NE, Case G, Kolb AW, Brandt CR: Multiple peptides homologous to herpes simplex virus type 1 glycoprotein B inhibit viral infection. Antimicrob Agents Chemother 2009, 53:987-996.

14. Backovic M, Jardetzky TS, Longnecker R: Hydrophobic residues that form putative fusion loops of Epstein-Barr virus glycoprotein B are critical for fusion activity. J Virol 2007, 81:9596-9600.

15. Galdiero S, Vitiello M, D'Isanto M, Falanga A, Cantisan M, Browne $H$, Pedone C, Galdiero M: The identification and characterization of fusogenic domains in herpes virus glycoprotein B molecules. Chembiochem 2008, 9:758-67.

16. Gianni T, Martelli PL, Casadio R, Campadelli-Fiume G: The ectodomain of herpes simplex virus glycoprotein $\mathrm{H}$ contains a membrane a-helix with attributes of an internal fusion peptide, positionally conserved in the Herpesviridae family. J Virol 2005, 79:2931-2940.

17. Osterrieder N, Kamil JP, Schumacher D, Tischer BK, Trapp S: Marek's disease virus: from miasma to model. Nat Rev Microbiol 2006, 4:283-294.

18. Jarosinski KW, Tischer BK, Trapp S, Osterrieder N: Marek's disease virus: lytic replication, oncogenesis and control. Expert Rev Vaccines 2006, 5:761-72.

19. Calnek BW, Witter RL: Neoplasic disease/Marek disease, in disease of poultry. IA: lowa State University Press, Ames; 1991, 342-385.

20. Wu P, Reed WM, Lee LF: Glycoproteins $\mathrm{H}$ and L of Marek's disease virus form a hetero-oligomer essential for translocation and cell surface expression. Arch Virol 2001, 146:983-92.

21. Yoshida S, Lee LF, Yanagida N, Nazerian K: Mutational analysis of the proteolytic cleavage site of glycoprotein B (gB) of Marek's disease virus. Gene 1994, 150:303-6.

22. Ding J, Cui Z, Jiang S, Li Y: Study on the structure of heteropolymer pp38/pp24 and its enhancement on the bi-directional promoter upstream of pp38 gene in Marek's disease virus. Sci China C Life Sci 2008, 51:821-6.

23. Galdiero S, Falanga A, Vitiello M, D'Isanto M, Cantisani M, Kampanaraki A, Benedetti E, Browne H, Galdiero M: Peptides containing membraneinteracting motifs inhibit herpes simplex virus type 1 infectivity. Peptides 2008, 29:1461-71.

24. Lee S, Ohashi K, Sugimoto C, Onuma M: Heparin inhibits plaque formation by cell-free Marek's disease viruses in vitro. J Vet Med Sci 2001, 63:427-32.

25. Woodruff AM, Goodpasture EW: The susceptibility of the chorio-allantoic membrane of chick embryos to infection with the fowl-pox virus. Am J Pathol 1931, 7:209-222.

26. Scher C, Haudenschild C, Klagsbrun M: The chick chorioallantoic membrane as a model system for the study of tissue invasion by viral transformed cells. Cell 1976, 8:373-82.

27. Siegel BV, Batts AA: Patterns of avian viral multiplication and associated membrane histopathology in the chorioallantois of developing chick embryo. Arch Gesamte Virusforsch 1957, 7:498-505.

28. Sharma JM, Coulson BD, Young E: Effect of in vitro adaptation of Marek's disease virus on pock induction on the chorioallantoic membrane of embryonated chicken eggs. Infect Immun 1976, 13:292-295.

29. Longenecker BM, Pazderka F, Stone HS, Gavora JS, Ruth RF: In ovo assay for Marek's disease virus and turkey herpesvirus. Infect Immun 1975, 11:922-31.

30. Buranathai C, Rodriguez J, Grose C: Transformation of primary chick embryo fibroblasts by Marek's disease virus. Virology 1997, 239:20-35.

31. Yakovleva LS, Mazurenko NP, Gunenkova NK, Vinogradov VN, Pavlovskaya Al, Chernyakhovskaya IY: Marek's disease virus (Kekava strain) replication in chickens, chick embryos and cell cultures. Acta Virol 1975, 19:293-8.

32. Wang XJ, Bai YD, Zhang GZ, Wang M, Gao GF: Structure and function study of paramyxovirus fusion protein heptad repeat peptides. Arch Biochem Biophys 2005, 436:316-322.

33. Okazaki K, Kida $H$ : A synthetic peptide from a heptad repeat region of herpesvirus glycoprotein B inhibits virus replication. J Gen Virol 2004 , 85:2131-7

34. Galdiero S, Falanga A, Vitiello G, Vitiello M, Pedone C, D'Errico G, Galdiero M: Role of membranotropic sequences from herpes simplex 
virus type I glycoproteins $\mathrm{B}$ and $\mathrm{H}$ in the fusion process. Biochim Biophys Acta 2010, 1798:579-91.

35. Atanasiu D, Whitbeck JC, de Leon MP, Lou H, Hannah BP, Cohen GH,

Eisenberg RJ: Bimolecular complementation defines functional regions of herpes simplex virus $\mathrm{gB}$ that are involved with $\mathrm{gH} / \mathrm{gL}$ as a necessary step leading to cell fusion. J Virol 2010, 84:3825-34.

36. Qian JF, Chen PY, Cai BX: Comparison of growth characteristics between Marek's disease virus and herpesvirus of turkey in chick embryonic cell culture. Chin J Virol 1992, 3:257-261.

doi:10.1186/1743-422X-8-190

Cite this article as: Wang et al: Structural characteristics and antiviral activity of multiple peptides derived from MDV glycoproteins B and $\mathrm{H}$. Virology Journal 2011 8:190.

\section{Submit your next manuscript to BioMed Central} and take full advantage of:

- Convenient online submission

- Thorough peer review

- No space constraints or color figure charges

- Immediate publication on acceptance

- Inclusion in PubMed, CAS, Scopus and Google Scholar

- Research which is freely available for redistribution

Submit your manuscript at www.biomedcentral.com/submit
() Biomed Central 